\title{
Development and Mechanical Testing of Porous-Lightweight Geopolymer Mortar
}

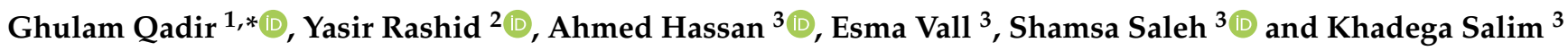 \\ 1 School of Civil Engineering, The University of Sydney, Camperdown, NSW 2006, Australia \\ 2 Fraunhofer Institute for Building Physics, 83626 Valley, Germany; yasir.rashid@tum.de \\ 3 Department of Architectural Engineering, United Arab Emirates University, P.O. Box 15551 Al Ain, UAE; \\ ahmed.hassan@uaeu.ac.ae (A.H.); 201350061@uaeu.ac.ae (E.V.); 201412375@uaeu.ac.ae (S.S.); \\ 201414086@uaeu.ac.ae (K.S.) \\ * Correspondence: ghulam.qadir@sydney.edu.au
}

check for

updates

Citation: Qadir, G.; Rashid, Y.; Hassan, A.; Vall, E.; Saleh, S.; Salim, K. Development and Mechanical Testing of Porous-Lightweight Geopolymer Mortar. Buildings 2021, 11, 1. https:/ / dx.doi.org/10.3390/ buildings11010001

Received: 17 November 2020

Accepted: 17 December 2020

Published: 22 December 2020

Publisher's Note: MDPI stays neutral with regard to jurisdictional claims in published maps and institutional affiliations.

Copyright: () 2020 by the authors. Licensee MDPI, Basel, Switzerland. This article is an open access article distributed under the terms and conditions of the Creative Commons Attribution (CC BY) license ( https://creativecommons.or g/licenses/by/4.0/).

\begin{abstract}
In this study, a novel porous geopolymer mortar (GP) was produced and tested experimentally. Industrial waste materials/by-products were used as constituents of the GP, along with dune sand. One sample was produced as a control sample for benchmarking. For the rest of the samples, $15 \%, 30 \%$, and $45 \%$ by volume, the solid constituents were replaced with expanded polystyrene foam (EPS) beads. These mortar samples were heat cured to depolymerize the EPS to cause porosity inside the samples. Indoor experiments were conducted to evaluate the response of produced porous GP to high heat flux. The porous samples were able to reduce heat transmission across the opposite surfaces. Induced porosity resulted in a decrement in compressive strength from $77.2 \mathrm{MPa}$ for the control sample to $15.8 \mathrm{MPa}$ for $45 \%$ porous sample. However, the limit lies within the standards for partitioning walls in buildings and pavements in urban areas to absorb rainwater.
\end{abstract}

Keywords: geopolymer mortar; porous concrete; heat transmission reduction; rainwater absorptive pavements; noise diffusion

\section{Introduction}

In global $\mathrm{CO}_{2}$ emissions, the cement industry alone contributes approximately $7 \%$ because of high-temperature processes involved in the production of cement [1]. This process is causing environmental degradation and increasing global warming as $\mathrm{CO}_{2}$ is a principal greenhouse gas [2]. Intense research efforts are taking place for discovering more eco-friendly coarse and fine aggregates and binder replacing cement [3]. After lime and Ordinary Portland cement (OPC), geopolymer (GP) is considered to be the thirdgeneration cement. In the recent past, GP has caught much attention because of its low permeability, early compressive strength, good chemical resistance, and excellent fire resistance behavior [4]. GP has a low carbon footprint than the conventional OPC [5]. Because of these characteristics, GP is a good substitute for OPC to develop sustainable products in the formulation of building materials; fiber enforced composites, fire-resistant coatings, and waste confinement solutions in nuclear and chemical industries. Recently, geopolymer concrete (GPC) has been tested by incorporating two different phase change materials (PCM) for improving building energy efficiency for the climatic conditions of Madrid, Spain, and Oslo, Norway. The study found 25-27\% reduction of the annual power consumption in space air-conditioning [6]. Experimental testing was done to find out the effects of lightweight expanded clay aggregate (LECA) and GP-coated expanded clay-phase change material (GP-L-PCM) capsules on thermal and structural performance of GPC. The composition of GP and other specimen variables were kept the same, using complete compaction LECA and GP-L-PCM were added at volumes; 25\%, 50\%, and 75\%. The heat transmission exhibition of LECA and GP-L-PCM slabs was low, shown by their low maximum surface temperatures. It was also found that the compressive strength in 
LECA and GP-L-PCM slabs decreased to a greater extent in comparison with GPC for all tested samples. The compressive strength reduced from 65.7 MPa for the reference sample to $10.1 \mathrm{MPa}$ for $75 \%$ LECA composition [7].

In another study, lightweight mortars based on cement, metakaolin (MK), ultrafine ground granulated blast furnace slag (UGGBFS), ceramic waste powder (CWP), and clay brick waste powder (CBWP) were studied. Two sets of mixes were prepared with two types of lightweight aggregate including LECA and pumice aggregate. The UGGBFS-based alkali-activated mortar with pumice aggregate exhibited the highest electrical resistivity and lowest water absorption. The scanning electron microscopy (SEM) images showed that UGGBFS-based mortar developed a dense matrix with a few pores, whereas incomplete geo-polymerization and voids were detected in CWP- and CBWP-based mortars [8]. Furthermore, alkali-activated lightweight concretes (AALWCs) were developed and compared with reference lightweight concrete (RLWC). The properties studied were compressive strength, flexural strength and splitting tensile strength. The results show that the AALWCs have superior durability properties than the RLWC. Also, the replacement ratios of 0,25 and $50 \%$ blast furnace slag (BFS) by weight of fly ash (FA) used in AALWCs had reduced environmental pollution and reducing $\mathrm{CO}_{2}$ emissions [9]. The thermal and structural performance of GP coated polyurethane foam-phase change material capsules/GPC composites were studied. Concrete composites (CC) were prepared and arranged in the three groups, namely pure geopolymer (GP, control sample), GP/polyurethane foam (F) CC, and GP-coated polyurethane foam-phase change material capsules (GP-F-PCM)/GP CC. The percentages of foam and GP-F-PCM capsules used in the composites were $25 \%$, $50 \%$, and $75 \%$, respectively. It was reported that the GP-F-PCM composite capsules were the best as a heat insulator among the investigated compositions [7]. In another study, rubberized geopolymer concrete (RGPC) was compared with OPC on performance evaluation parameters e.g., compressive strength, split tensile strength, modulus of elasticity, flexural strength, pull off strength and durability parameter (abrasion resistance). The outcome of the comparison showed that RGPC is superior to OPC in all parameters [3]. Ground granulated blast furnace Slag (GGBS) entirely replaced cement. Considering concrete's fragility, to improve its performance, steel and glass fibers were reinforced. The experimental test showed a symbolic upgrade in flexural strength, stiffness degradation, cumulative energy dissipation capacity, displacement ductility, and the extreme load with its corresponding deflection [10]. In Brazil, the mechanical performance of precast beams of reinforced geopolymer concrete (CCG) and the comparison with their duplicates of reinforced Portland cement concrete (CCP) was done, and it was found that the effect of reinforcement ratio on precast CCG beams is approximately identical with typical precast $\mathrm{CCP}$ beams in regards to flexural capacity and ductility. The extreme load-carrying capacity of CCG precast beams was slightly higher when compared to CCP precast beams [11]. To produce geopolymer earth brick (GPEB), strength development for various grades of geopolymer mortar was done with varying molarity. The study found that brick is made by fly ash (FA) and GGBS as binders and soil and quarry dust as fine aggregate in a ratio of 0.5:0.5:1.75:0.25 with fibrous coir waste $1 \%$ and alkaline solution of $10 \mathrm{M}$ for preparing mortar to produce, fine compressive strength, little water absorption, low rate of absorption, acceptable abrasive resistance etc., cement (OPC)-based mortar. FA, GGBS, sandy soil sieved from earth and quarry dust (QD) [12].

For energy interventions and seismic retrofitting, a lightweight cement-free reinforced plaster was developed [13]. It was found that the 28-day compressive strength of the developed plaster was $8 \mathrm{MPa}$ compared to 2-2.5 MPa of traditional plaster. In another study, microstructure and mechanical properties e.g., flexural strength, flexural modulus of fabric reinforced GP composite after their exposure to high temperature (up to $1000^{\circ} \mathrm{C}$ ) were studied. It was revealed that with increase of processing temperature after $600^{\circ} \mathrm{C}$, the residual strength of carbon-based geo-polymer composite increases. At high processing temperature, the basalt reinforced geo-polymer composite strength decreases. For high 
thermal temperature applications in thermal barrier coatings and panels, carbon reinforced geo-polymer composite can be a good choice [14].

Studies associated with concrete-related issues approach various types of building materials with polystyrene granule, such as mortar, concrete, pavement, etc. The effects of polystyrene granule in concrete depend on its type (cement-based concrete or polymer-based concrete), quantity and form of polystyrene, etc. Mostly the mechanical characteristics decrease with an increase in polystyrene dosage. Some studies have shown that thermal treatment of polystyrene upgrades concrete behavior, respectively the aspects related to workability, density, thermal conductivity, and shrinkage [15] because the thermal conductivity ( $k$-value) of the polystyrene insulation is undoubtedly changed by its moisture content at various operating temperatures [16]. An experiment in which concrete that contained FA and polystyrene granules substituted for aggregates, in quantities ranging from $20 \%$ to $100 \%$ volume was conducted, and it was found that polystyrene granules improved the workability of fresh concrete and decreased density but the distribution of polystyrene granules in concrete mass was not homogeneous and granules had the tendency to flow, specifically for higher dosages [17].

A myriad of research articles are present about heat curing of GPC with considerable variations in their findings, e.g., Adam and Horianto reported almost no or minimal increment in the strength development from the age of 7 to 28 days when the samples were air cured [18]. However, another study presented a continuous strength enhancement of all the air-cured compositions when they were tested at the age of $3,7,28,56,90$, and 180 days [19]. Muhammad et al. reported a decrease in compressive strength from age 3 to 7 days when GP samples were heat cured at $60^{\circ} \mathrm{C}, 70{ }^{\circ} \mathrm{C}, 80^{\circ} \mathrm{C}$ and $100{ }^{\circ} \mathrm{C}$, but the strength increased again from 7 to 28 days [20]. On the contrary, Al-Majidi reported a continuous increment in compressive strength when the heat-cured samples were tested at the age of 3 and 7 days, while for air curing, the same pattern of strength development was observed at the age of $3,7,14$, and 28 days [21]. Furthermore, the same publication reported almost no difference in the compressive strength at the age of 28 days, whether the samples are heat-cured or ambient-cured [21]. However, Ismail and El-Hassan reported a significant difference in compressive strength between heat-cured and ambient-cured samples at 28 days. The variation was around $28.5 \%$ for one set of conditions at the value of around $112 \mathrm{MPa}$ for the heat-cured sample [22]. In the current study, heat curing of GP is employed not to answer the questions entailing the effect of heat curing onto compressive strength but to instill porosity into the GP.

This research study focuses on the development of porous GP for future applications in energy-efficient building envelopes, absorptive rainwater pavements, noise diffusion in buildings, and across highways crossing the localities. The effect of porosity on thermal and structural performance is evaluated and reported.

\section{Materials and Methods}

The following sections cover the materials used in the experiments while reporting the compositions of the materials. The specimen preparation and the testing methods are also described.

\subsection{Materials}

The elements of the dry mix were ground granulated blast furnace slag (GGBS), fly ash (FA), and dune sand (DS). Photographs of the materials and the development process of the samples are shown in Figure 1. GGBS was provided by a local industry called Emirates Cement Factory in Al Ain city of the United Arab Emirates (UAE). FA was also procured locally from Ashtech International in Dubai, UAE. DS was collected from the close-by desert in Al Ain, UAE. Prior to the experiments, the compositions of GGBS, FA, and DS were analyzed using X-ray Fluorescence (XRF, Lab Center XRF-1800, Shimadzu Corporation, Kyoto, Japan) and X-ray Diffraction (XRD, PW /1840, Philips, Amsterdam, The Netherlands) techniques [23], and the corresponding compositions are presented in 
Table 1 for the completeness of the results. The size distribution curves of these materials are reported in [22]. The bonding reaction (geo-polymerization) was activated by an alkaline solution of sodium hydroxide $(\mathrm{NaOH})$ and sodium silicate $\left(\mathrm{Na}_{2} \mathrm{SiO}_{3}\right)$.
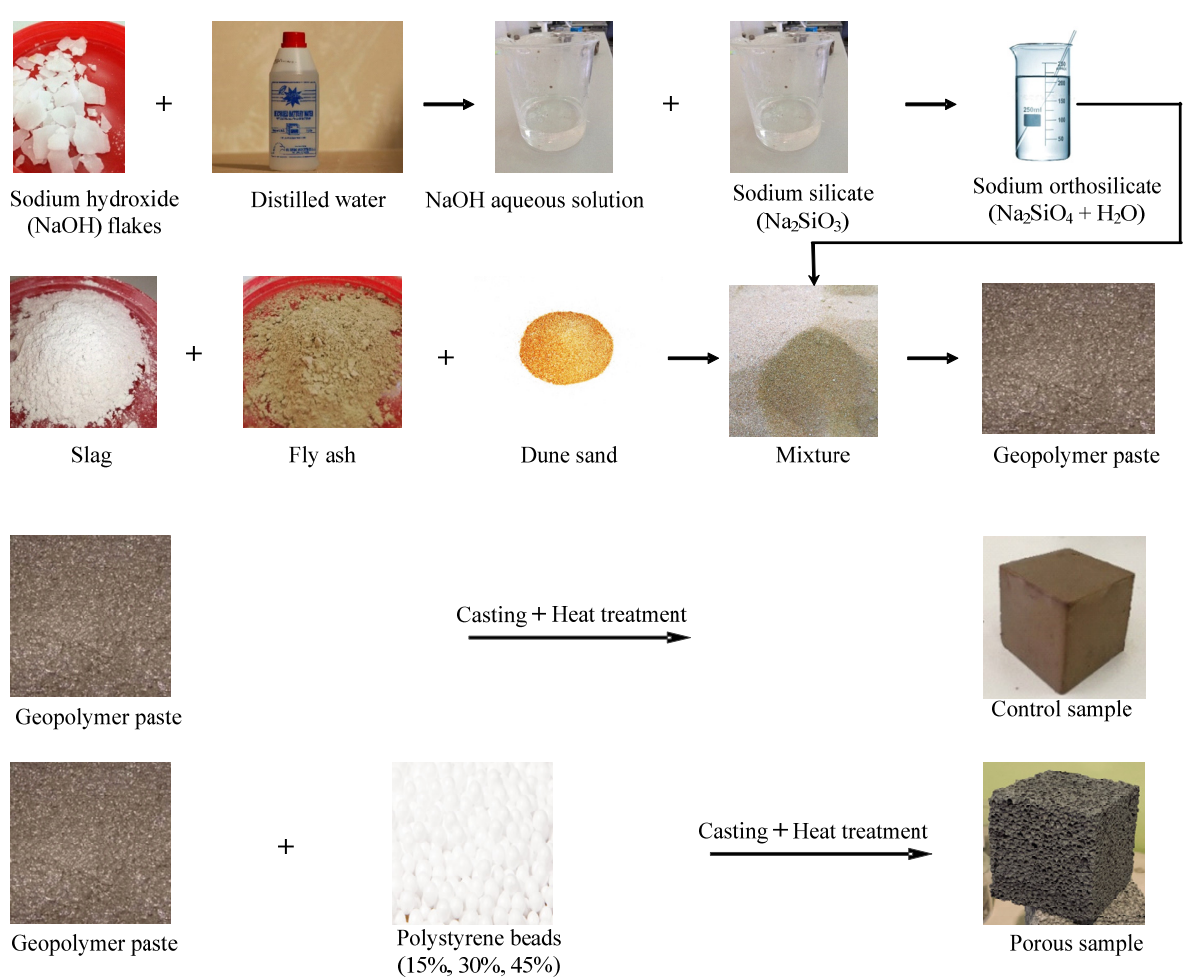

Figure 1. Photographs of the raw materials and the process of development of the samples.

Table 1. Material properties with procurement sources used in the development of specimens.

\begin{tabular}{|c|c|c|c|c|}
\hline Material & Source & Main Components & Proportions & Density $\left(\mathrm{kg} / \mathrm{m}^{3}\right)$ \\
\hline Dune sand (DS) & $\mathrm{Al}$ Ain (UAE) & $\begin{array}{l}\mathrm{SiO}_{2} \\
\mathrm{CaO} \\
\mathrm{Al}_{2} \mathrm{O}_{3}\end{array}$ & $\begin{array}{c}63.9 \% \\
14.1 \% \\
3 \%\end{array}$ & 1693 \\
\hline Fly Ash (FA) & $\begin{array}{l}\text { Ashtech International } \\
\text { (Dubai, UAE) }\end{array}$ & $\begin{array}{c}\mathrm{SiO}_{2} \\
\mathrm{Al}_{2} \mathrm{O}_{3} \\
\mathrm{Fe}_{2} \mathrm{O}_{3}, \mathrm{CaO}\end{array}$ & $\begin{array}{c}48 \%, \\
23.1 \%, \\
12.5 \% \\
3.3 \%\end{array}$ & 1262 \\
\hline $\begin{array}{l}\text { Ground granulated blast } \\
\text { furnace slag (GGBS) }\end{array}$ & $\begin{array}{l}\text { Emirates Cement factory } \\
\text { (Al Ain, UAE) }\end{array}$ & $\begin{array}{c}\mathrm{CaO} \\
\mathrm{SiO}_{2} \\
\mathrm{Al}_{2} \mathrm{O}_{3}, \mathrm{MgO}\end{array}$ & $\begin{array}{c}42 \%, \\
34.7 \%, \\
14.4 \%, \\
6.9 \%\end{array}$ & 1236 \\
\hline Sodium silicate solution & $\begin{array}{c}\text { Sigma-Aldrich } \\
\text { (St. Louis, MO, USA) }\end{array}$ & - & - & - \\
\hline Sodium hydroxide & $\begin{array}{c}\text { Sigma-Aldrich } \\
\text { (St. Louis, MO, USA) }\end{array}$ & - & - & - \\
\hline
\end{tabular}

\subsection{Specimen Preparation}

The mass ratio of the GGBS, FA, and DS was kept constant at 1:3:6, which was optimized earlier, as reported in [7]. Molarity of the $\mathrm{NaOH}$ solution (18 M) and mass proportions of $\mathrm{NaOH}$ to $\mathrm{Na}_{2} \mathrm{SiO}_{3}$ was kept constant as 1:2.5, which was optimized in an earlier study [22]. The mass ratio of the alkaline solution to the dry mix was 1:3. 
GGBS, FA, and DS were weighted and mixed until homogenization was achieved. $18 \mathrm{M} \mathrm{NaOH}$ and $\mathrm{Na}_{2} \mathrm{SiO}_{3}$ were mixed in the defined mass ratio separately. Solid and liquid constituents were later mixed slowly while regular stirring until the complete homogenization was achieved. The yield of this process was a homogenous paste. The paste was cast into the steel cubes $(50 \mathrm{~mm} \times 50 \mathrm{~mm} \times 50 \mathrm{~mm})$ by proper compaction to avoid entrapping of air bubbles in the samples. The sequence of samples development with mixing proportions are shown in the flow chart in Figure 2.

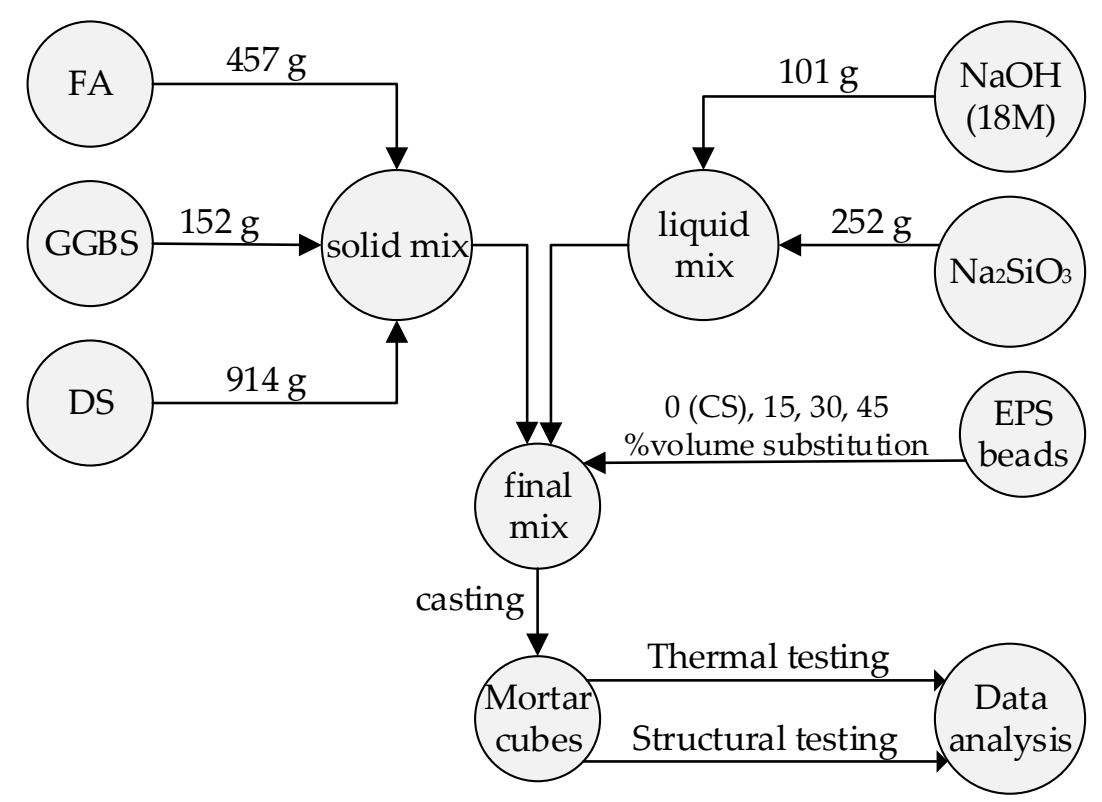

Figure 2. Flowchart diagram representing the sequence and mix proportions of the constituents of the GP and complete experimentation process; CS—control sample.

For the other samples, $15 \%, 30 \%$, and $45 \%$ of the geopolymer volume were replaced with expanded polystyrene foam (EPS) beads. The samples with respective porosity are named $15 \%, 30 \%$, and $45 \%$ throughout this. All the samples were cast into the molds at the same laboratory conditions, including illumination (no direct sunlight) and temperature $\left(25^{\circ} \mathrm{C}\right)$ to avoid any possible effect of external factors. All samples were kept in the molds for $24 \mathrm{~h}$ after casting, then unmolded and heat cured at $350{ }^{\circ} \mathrm{C}$ for $24 \mathrm{~h}$ in an oven. A temperature of $350{ }^{\circ} \mathrm{C}$ was achieved before adding samples into the oven. After heat curing, the samples were kept in the same laboratory conditions for further aging until respective thermal and structural testing.

\subsection{Induction of Porosity in Geopolymer}

The idea of generating a porous structure by decomposing EPS came from a failed experiment in which an enclosure of EPS (10 cm thick) was constructed, and a 100-Watt fluorescent bulb was lit inside to gain a little temperature. Rather than gaining temperature, the closer side of EPS to the bulb was decomposed within a few minutes, which inspired the idea to use the same phenomenon in the production of lightweight porous geopolymer. In one sense, the idea is analogous to the production of expanded clay aggregate, in which clay is exposed to high temperature (around $1200^{\circ} \mathrm{C}$ ), which causes some minerals to decompose, emitting gases, and developing porosity in the structure [24].

Heat curing at $350{ }^{\circ} \mathrm{C}$ caused the EPS embedded inside the GP cubes to depolymerize. The de-polymerization process causes the EPS to deform, which consists of $2 \%$ by volume of the styrene polymer and 98\% air [25]. Schneider et al. explained the production process of EPS by informing that polystyrene achieves $5000 \%$ volume expansion during its production [26]. Heating causes the EPS to deform and shrink; the same effect has been exploited in the current research to induce porosity in the GP. A similar mechanism 
(called lost foam casting) has been used in many manufacturing industries (General Motors, Mercury Marine, BMW, and Kohler etc.) for years to cast complex net-like metal structures where EPS is taken out through the vents after pouring metal into the mold [27]. Contrary to the metal manufacturing facilities, deformed EPS stayed inside the GP cubes in the current research.

\subsection{Thermal Performance Set-Up}

For thermal experiments, a very thin additional layer of the same GP was applied to the surfaces of the porous GP cubes to close porosity on the outer surfaces. It was done to stop air movement through the samples during thermal testing. An insulation chamber was designed to conduct thermal experiments. The samples were tested one at a time, kept at a $20 \mathrm{~cm}$ distance from a heating source. The heating source was connected to a constant powered power supply during the heating phase. The distance between the heating plate and the sample surface was calculated in such a way that approximate $1 \mathrm{~kW} / \mathrm{m}^{2}$ radiations strike at the surface of the samples. Just one surface was exposed to the radiation, which is named the front surface. The opposite surface was exposed to a fixed temperature chamber, and the surface is called the back surface. All the other four surfaces were properly insulated. It is assumed that the total heat transfer is 1-Dimensional (1-D) from the heating flux exposed front surface to the fixed temperature exposed back surface. Transient temperatures were measured using k-type thermocouples (RS Components, Corby, UK) at all the surfaces, and the data was logged using data acquisition system compact DAQ (NIcDAQ-9178, Austin, Texas, United States), which was interfaced with LabVIEW software (LabVIEW 2016, Austin, Texas, United States). Data from all the samples were compared against the same time scale, which was tested individually otherwise. The experimental set-up and schematic diagram are shown in Figure 3.

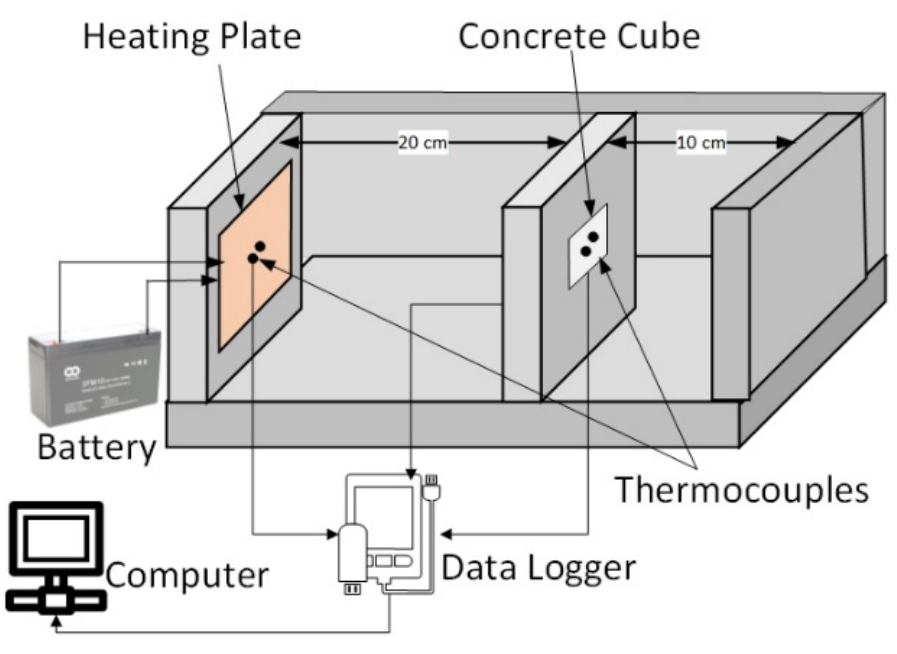

(a)

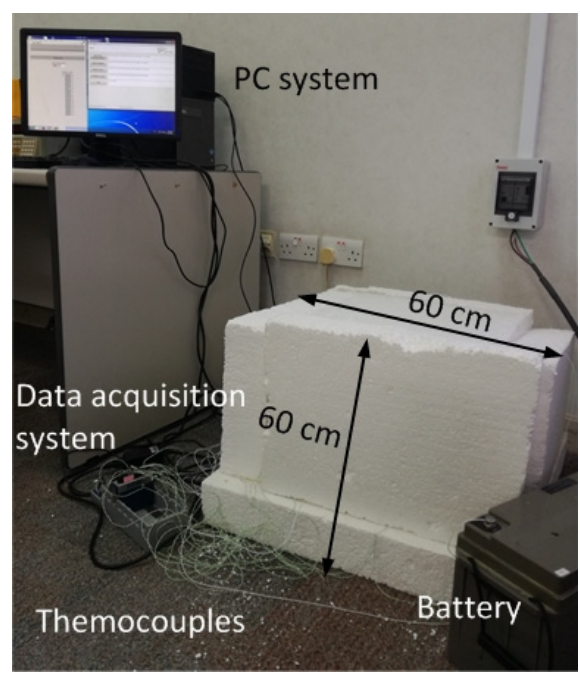

(b)

Figure 3. Experimental set-up for thermal performance measurement; (a) schematic diagram (b) original photo.

\subsection{Heat Transfer Analysis}

The difference in surface temperature with different porosity levels is hard to visualize in terms of energy-saving potential. To visualize the energy-saving, the cooling load reduction is calculated theoretically while considering some valid assumptions. An enclosure with a heated wall surface area of $1 \mathrm{~m}^{2}$ is considered while all other walls, floor, and ceiling are assumed at a fixed temperature which is equivalent to the human thermal comfort $\left(25^{\circ} \mathrm{C}\right)$. In the calculation, the temperature of the heated surface is taken as the average back-surface temperature for the reference, $25 \%, 50 \%$, $75 \%$ samples individually. The 
reference temperature for enclosed air is taken as $25^{\circ} \mathrm{C}$. The well-suited correlation for the convective heat transfer coefficient $\left(h_{c}\right)$ is taken from Awbi, as presented in Equation (1) [28].

$$
h_{c}=1.823 \frac{\Delta T^{0.293}}{D^{0.121}}
$$

where $\Delta T$ is the temperature difference (in $\mathrm{K}$ ) of the back-surface of the wall and reference air in contact with the wall, and $D$ is the hydraulic diameter (in $\mathrm{m}$ ). For the back-surface temperature, an average value for each individual sample was considered. The amount of heat transferred from the heated surface to the indoor space ( $Q_{t h}$ in Watts) is calculated using Equation (2). Radiative energy is not considered because of considerably less magnitude compared to convective energy. Here $A$ is the surface area (in $\mathrm{m}^{2}$ ).

$$
Q_{t h}=h_{c} A \Delta T
$$

\subsection{Compressive Strength Testing}

To curtail external effects variations, the specimens were placed in identical indoor conditions during preparations and curing. In total, 40 samples were tested at the age of 7 and 28 days. Five samples for each case were tested, and average values were used for the compressive strength calculations. A $2000 \mathrm{kN}$ universal testing machine was used to test the compressive strengths of all specimens while applying the load. The strain endpoint and test point values were $0.8 \mathrm{~mm} / \mathrm{min}$ and $1.00 \mathrm{~mm} / \mathrm{min}$, respectively.

\section{Results and Discussion}

The primary point of interest in developing lightweight, porous GP was to examine its thermal performance while complying with the structural strength standards. The following sections contain the results of the investigations.

\subsection{Thermal Performance}

Figure 4 represents the comparison of the temperature profiles for front surfaces. At the start of the experiment, specimens were at room temperature, which started rising at different rates when the heat flux was applied. The rise in surface temperature for all specimens was different because of possessing different material properties depending on the different amounts of porosity, but the overall pattern was the same. Steady-state temperature for the reference (control sample) cube was achieved at $78.5^{\circ} \mathrm{C}$, while it was $71.4^{\circ} \mathrm{C}, 68.6^{\circ} \mathrm{C}$, and $64.1{ }^{\circ} \mathrm{C}$ with the porosity of $15 \%, 30 \%$, and $45 \%$, respectively.

Back surfaces showed similar temperature profiles as the front surface; however, with a reduced magnitude of steady-state temperatures, as shown in Figure 5. The control sample achieved its steady state at $68.4^{\circ} \mathrm{C}$ while it was $63.8^{\circ} \mathrm{C}, 59.5^{\circ} \mathrm{C}$, and $57.2{ }^{\circ} \mathrm{C}$ for $15 \%, 30 \%$, and $45 \%$, respectively. The variation in temperature profile is due to the variation in thermal conductivity caused by the porosity, in agreement with the literature [29]. The difference in these temperatures for the maximum cases, i.e., control sample and $45 \%$ porosity, are $11.2^{\circ} \mathrm{C}$, which can play a significant role in energy saving in buildings. This decrease in the back-surface temperature is a parameter of interest in reducing the cooling load demand of a building [30,31]. Reduction in the back-surface temperature implies that the effective thermal conductivity of the porous GP is low. It is due to the presence of air in the voids, and the thermal conductivity of air is relatively low [6]. This less surface temperature will emit less heat through convection and radiation to the indoor spaces when used as a wall material, hence, contributing to energy-efficient building designs.

For other surfaces, similar temperature profiles were observed. However, the steadystate temperatures were in-between the temperatures for front and back surfaces. It verifies that the placement of the thermocouples was nearly accurate in the middle of the surfaces, and heat conduction was linear 1-D. The temperature comparison of all the samples on the one-side surface is represented in Figure 6. To avoid redundancy, the steady-state 
temperatures for the other three surfaces along with the plotted surfaces are summarized in Table 2.

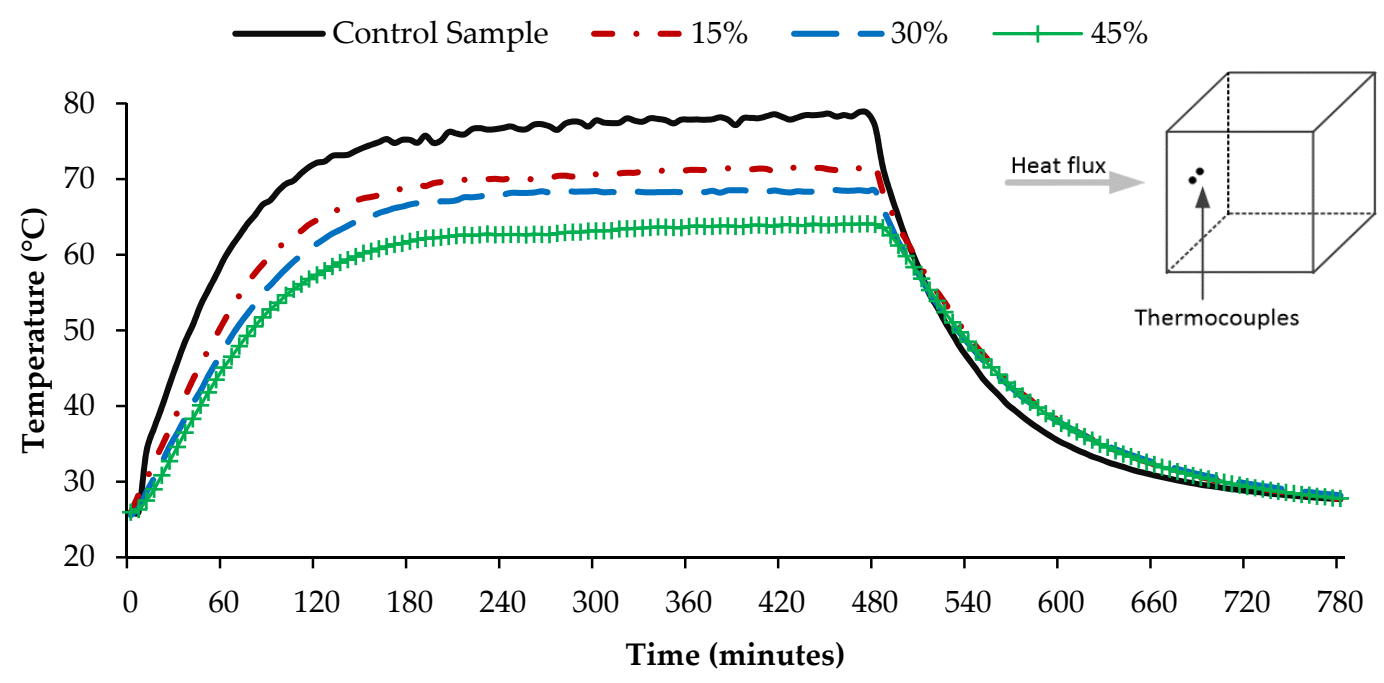

Figure 4. Comparison of the front-surface temperatures for $15 \%, 30 \%, 45 \%$ with the control sample.

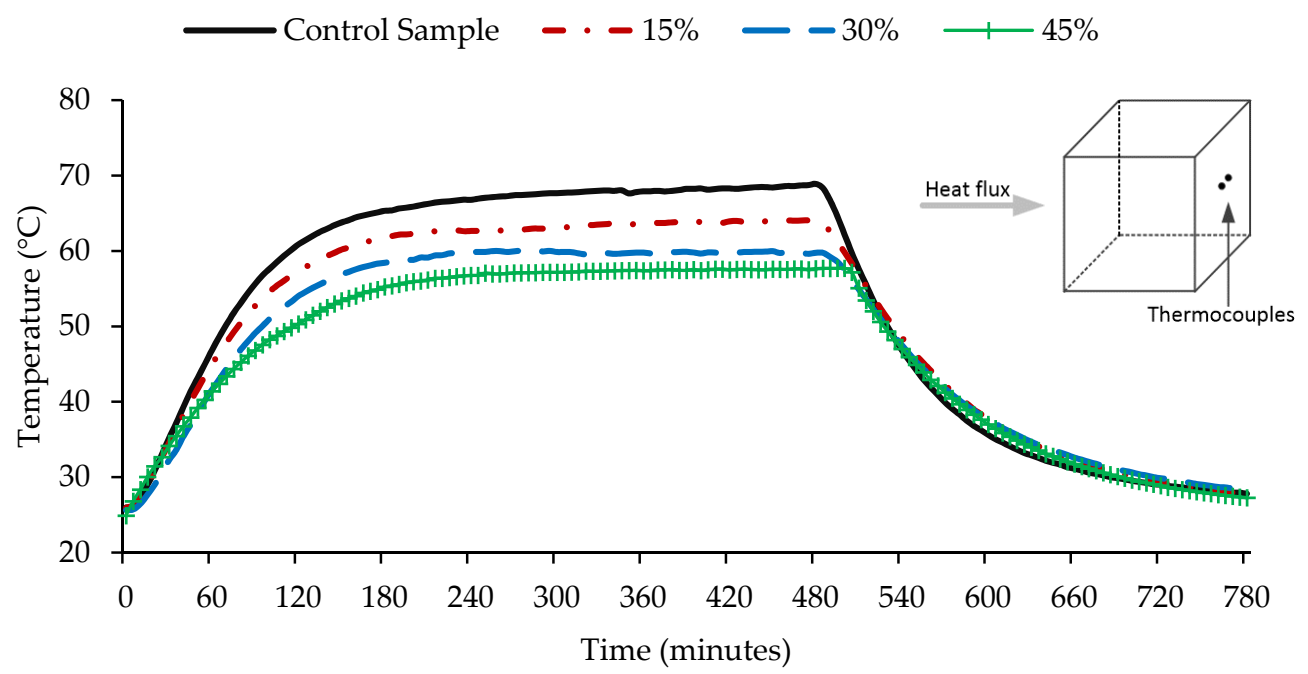

Figure 5. Comparison of the back-surface temperatures for $15 \%, 30 \%, 45 \%$ with the control sample.

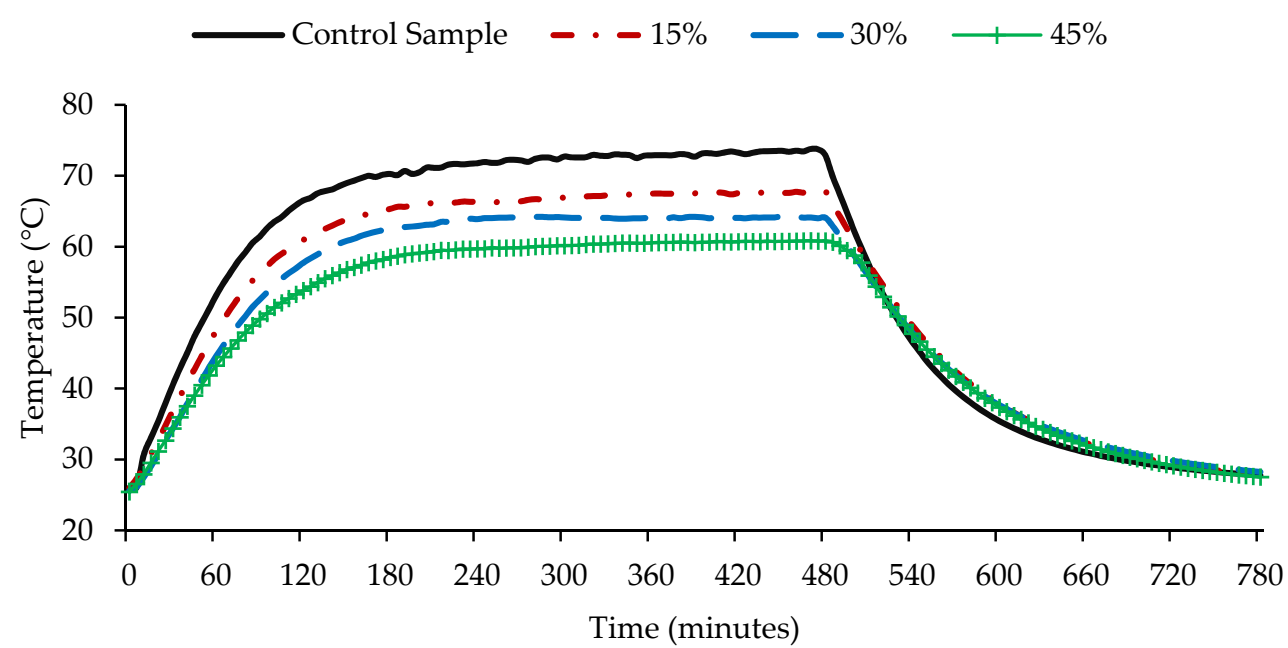

Figure 6. Comparison of the temperatures on one-side for $15 \%, 30 \%, 45 \%$ with the control sample. 
Table 2. Steady-state temperatures at different surfaces for all the samples.

\begin{tabular}{ccccc}
\hline & Control Sample $\left({ }^{\circ} \mathbf{C}\right)$ & $\mathbf{1 5 \%}\left({ }^{\circ} \mathbf{C}\right)$ & $\mathbf{3 0} \%\left({ }^{\circ} \mathbf{C}\right)$ & $\mathbf{4 5 \%}\left({ }^{\circ} \mathbf{C}\right)$ \\
\hline Front surface & 78.5 & 71.4 & 68.6 & 64.1 \\
Back surface & 68.4 & 63.8 & 59.5 & 57.2 \\
Side 1 (Top Surface) & 73.5 & 68.0 & 63.6 & 61.2 \\
Side 2(Down Surface) & 74.1 & 67.4 & 63.3 & 59.9 \\
Side 3 (Left Surface) & 73.8 & 67.9 & 64.3 & 60.8 \\
Side 4 (Right Surface) & 73.7 & 67.1 & 64.1 & 60.6 \\
\hline
\end{tabular}

\subsection{Cooling Load Reduction}

Based on the assumption, radiative heat transfer was ignored and convective heat transfer from the heated wall to the confined space was calculated. This energy transfer is affected by multiple factors in real scenarios, e.g., non-uniformity of the reference temperature, characteristic length or hydraulic diameter, obstructions present in the indoor spaces, opening/closing of doors, movement of human beings. However, the used correlation gives results up to a good accuracy with a lot of simplicity [32].

Calculation results are presented in Figure 7 where calculated heat transfer coefficients $\left(h_{c}\right)$ for all cases are presented on the primary-axis while the amount of heat transferred from $1 \mathrm{~m}^{2}$ surface area of the heated wall to the indoor space is presented on the secondary-axis. Value of $h_{c}$ was $4.52 \mathrm{~W} / \mathrm{m}^{2} \mathrm{~K}, 4.46 \mathrm{~W} / \mathrm{m}^{2} \mathrm{~K}, 4.36 \mathrm{~W} / \mathrm{m}^{2} \mathrm{~K}$ and $4.26 \mathrm{~W} / \mathrm{m}^{2} \mathrm{~K}$ for Reference, $15 \%, 30 \%$ and $45 \%$ samples respectively. This change in values is because of the difference in the average surface temperature of the samples. The amount of thermal energy $\left(Q_{t h}\right)$ transferred from the heated wall to the indoor space through convection was $123 \mathrm{~W}_{t h}$, $113 \mathrm{~W}_{\text {th }}, 101 \mathrm{~W}_{\text {th }}$ and $92 \mathrm{~W}_{\text {th }}$, respectively. It implies that going from solid composition to the $45 \%$ porous composition of one single wall, $23.5 \%$ of the cooling load per $\mathrm{m}^{2}$ can be reduced.

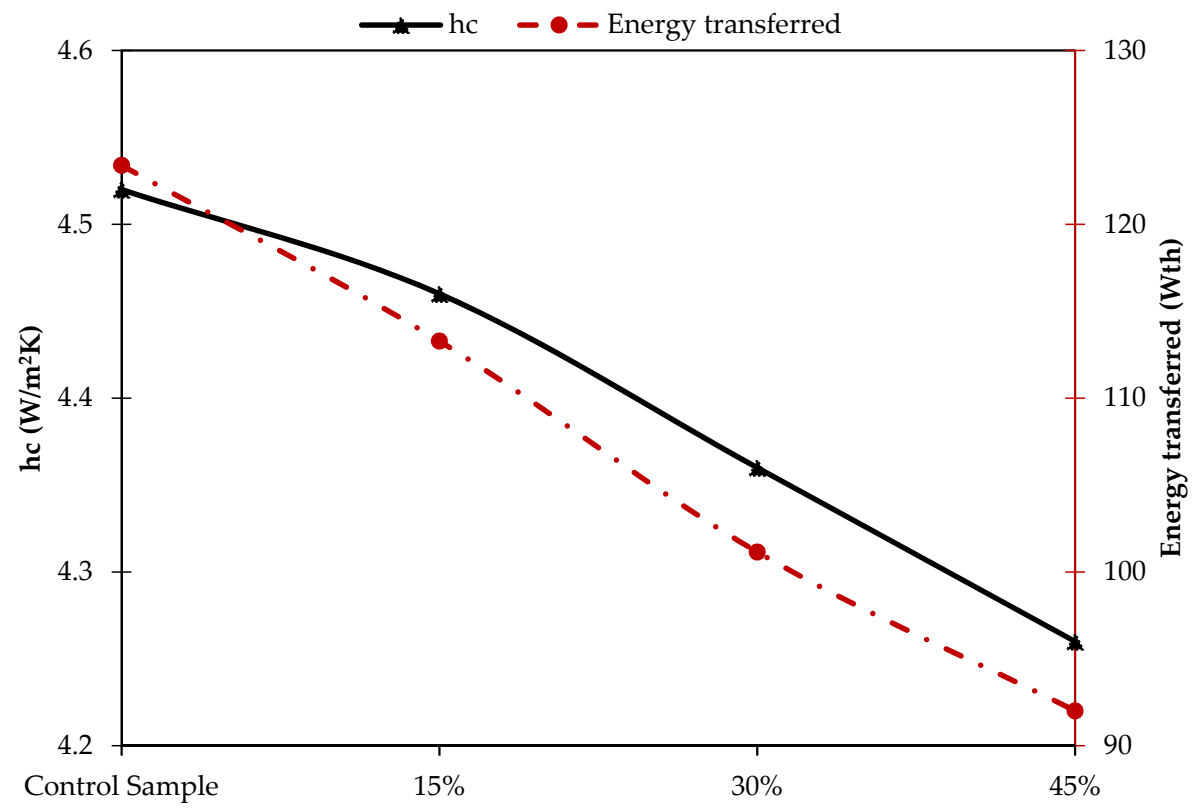

Figure 7. Convective heat transfer coefficient for indoor space on the primary axis and the amount of heat transferred from $1 \mathrm{~m}^{2}$ surface area of the heated wall to the confined space on secondary axis.

\subsection{Porosity Distribution and Density}

The uniformity of the distribution of EPS beads and hence governed uniform interlinked porosity was evident while performing destructive testing of the samples. Furthermore, masses of the samples also reflected uniformity to each class of the samples. For the control sample, the average mass was $291 \mathrm{~g}$ while it was $160 \mathrm{~g}$ for $45 \%$ porosity. Corre- 
sponding average densities of the control sample, $15 \%, 30 \%$ and $45 \%$ were $2328 \mathrm{~kg} / \mathrm{m}^{3}$, $1978 \mathrm{~kg} / \mathrm{m}^{3}, 1630 \mathrm{~kg} / \mathrm{m}^{3}$ and $1280 \mathrm{~kg} / \mathrm{m}^{3}$ respectively.

\subsection{Compressive Strength}

Figure 8 shows the compressive strength of the specimen at 7 and 28 days. In general, the strength of all samples increased with aging. For the control sample, the strength was $62.1 \mathrm{MPa}$ at 7 days, and it increased $24 \%$ by aging to the value of $77.2 \mathrm{MPa}$ at 28 days. In an earlier study, the same composition was tested without heat curing of the samples, and the corresponding compressive strength at the age of 7 and 28 days was $41.5 \mathrm{MPa}$ and $65.7 \mathrm{MPa}$ [7]. It implies that heat curing increased the rate of reaction for geo-polymerization, causing an early age strength. Later, the rate of development of strength from 7 to 28 days was slower. When used the geopolymer mortar without porosity, the strength is considerably high what is required for most of the construction components. By introducing porosity, strength dropped significantly. At 28 days, it was 26.4 MPa, 22.1 MPa, and 15.8 MPa for the porosity of $15 \%, 30 \%$, and $45 \%$, respectively. The reason for the strength reduction is the inconsistency of the solid structure throughout the bulk and the presence of air voids as porosity.

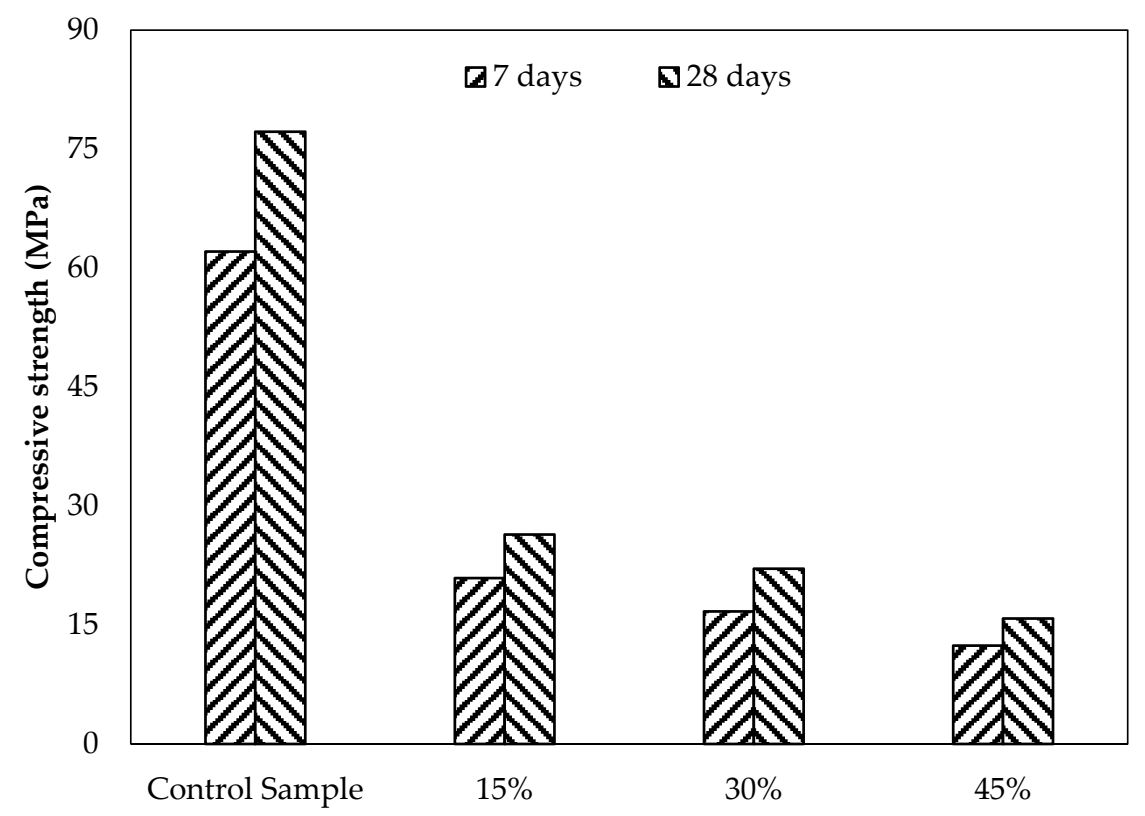

Figure 8. Comparison of compressive strength for the porous sample with the control sample.

\section{Discussion}

There is a wide range of applications for the newly developed porous GP. The primary intention of the development of porous GP was to use it for building applications. The compressive strength achieved in the experiments complies with the international standard ASTM C129-17 and can be used for non-load bearing building components, including outer partitioning walls and cladding [33]. It is evident from energy calculations that the newly produced GP will help in transmitting less heat to the indoor environment in hot climatic conditions enabling reducing the cooling load in buildings.

The developed concrete with $30 \%$ or less porosity can be directly used for pavements for light traffic complying with the standard ASTM C902-15, which restricts the minimum compressive strength to $17.2 \mathrm{MPa}$ in a less severe environment [34]. There has recently been a lot of work done on the development and mechanical testing of porous concrete [35,36]. The need for porous pavements is justified in urban areas due to the fact of absorbing rainwater into the soil, reducing burden onto the sewerage systems, retentions of pollutants, avoiding pollutants to mix with groundwater bank, and drivers safety $[36,37]$. 
Another potential application of the porous geopolymer mortar is in acoustics for noise reduction. The porosity helps in reducing, diffusing, and absorbing the unwanted noise, which has otherwise adverse effects on human wellbeing and work productivity [38]. It is anticipated that the produced porous GP, when used in buildings, will help in the low transmission of noise indoors. The sample GP can also be used as partitioning walls across the highways passing through the localities to restrict traffic noise reaching the localities. All these applications have well-proven advantages over typical concrete pavements and solid wall constructions.

\section{Conclusions}

In this study, novel porous geopolymer mortar (GP) is produced and tested experimentally. Porosity was induced into the samples by adding expanded polystyrene foam (EPS) beads into the concrete mix by $15 \%, 30 \%$, and $45 \%$ by volume substitution and subsequently heat-treated at $350{ }^{\circ} \mathrm{C}$ for $12 \mathrm{~h}$ to depolymerize the EPS. Indoor tests were conducted to observe the thermal behavior of the produced porous GP in comparison to the solid control sample. Air entrapped in the porous mortar caused a reduction of heat transmission, and a difference of $11.2{ }^{\circ} \mathrm{C}$ at the maximum was achieved at the back surface when compared to the control sample with $45 \%$ porous sample. The reduced temperature can reduce the cooling load of the indoor space by $23.5 \%$. Samples were tested structurally for compressive strength, which revealed a drop in strength with porosity. However, up-to $45 \%$ porous mortar is capable of complying with the non-loadbearing building components such as partitioning outer walls, and up to $30 \%$ porous mortar meets the standard requirements to be used in rainwater absorptive pavements and walkways for light traffic and noise reduction wall panels. Further research is underway to optimize the production process of porous geopolymer to make it energy economical.

Author Contributions: Conceptualization, A.H., G.Q.; methodology, G.Q., E.V., S.S., K.S.; formal analysis, G.Q. and Y.R.; data curation, G.Q. and Y.R.; writing-original draft preparation, G.Q., Y.R.; writing-review and editing, G.Q. and Y.R.; supervision, A.H. All authors have read and agreed to the published version of the manuscript.

Funding: This research was funded by the United Arab Emirates University through "Summer Undergraduate Research Experiences (SURE) PLUS Grant-2018".

Acknowledgments: The authors would like to express their appreciation to the United Arab Emirates University (UAEU) for the funding of this research as well as the Faculty of Engineering at UAE University for facilitating the experiments.

Conflicts of Interest: The authors declare no conflict of interest.

\section{References}

1. Summerbell, D.L.; Barlow, C.Y.; Cullen, J.M. Potential reduction of carbon emissions by performance improvement: A cement industry case study. J. Clean. Prod. 2016, 135, 1327-1339. [CrossRef]

2. Law, D.W.; Adam, A.A.; Molyneaux, T.K.; Patnaikuni, I.; Wardhono, A. Long term durability properties of class F fly ash geopolymer concrete. Mater. Struct. 2015, 48, 721-731. [CrossRef]

3. Luhar, S.; Chaudhary, S.; Luhar, I. Development of rubberized geopolymer concrete: Strength and durability studies. Constr. Build. Mater. 2019, 204, 740-753. [CrossRef]

4. Li, C.; Sun, H.; Li, L. A review: The comparison between alkali-activated slag (Si+Ca) and metakaolin (Si+Al) cements. Cem. Concr. Res. 2010, 40, 1341-1349. [CrossRef]

5. Gluth, G.J.G.; Rickard, W.D.A.; Werner, S.; Pirskawetz, S. Acoustic emission and microstructural changes in fly ash geopolymer concretes exposed to simulated fire. Mater. Struct. 2016, 49, 5243-5254. [CrossRef]

6. Cao, V.D.; Pilehvar, S.; Salas-Bringas, C.; Szczotok, A.M.; Bui, T.Q.; Carmona, M.; Rodriguez, J.F.; Kjøniksen, A.-L. Thermal analysis of geopolymer concrete walls containing microencapsulated phase change materials for building applications. Sol. Energy 2019, 178, 295-307. [CrossRef]

7. Rashid, Y.; Hassan, A.; Mourad, A.-H.; Ismail, N.; Laghari, M. Thermal and Structural Characterization of Geopolymer-Coated Polyurethane Foam-Phase Change Material Capsules/Geopolymer Concrete Composites. Materials 2019, 12, 796. [CrossRef] 
8. Ameri, F.; Shoaei, P.; Zareei, S.A.; Behforouz, B. Geopolymers vs. alkali-activated materials (AAMs): A comparative study on durability, microstructure, and resistance to elevated temperatures of lightweight mortars. Constr. Build. Mater. 2019, $222,49-63$. [CrossRef]

9. Sarıdemir, M.; Çelikten, S. Investigation of fire and chemical effects on the properties of alkali-activated lightweight concretes produced with basaltic pumice aggregate. Constr. Build. Mater. 2020, 260, 119969. [CrossRef]

10. Daniel, A.J.; Sivakamasundari, S.; Abhilash, D. Comparative Study on the Behaviour of Geopolymer Concrete with Hybrid Fibers under Static Cyclic Loading. Procedia Eng. 2017, 173, 417-423. [CrossRef]

11. Pires, E.F.C.; Lima, T.V.; Marinho, F.J.V.; de Vargas, A.S.; Mounzer, E.C.; Darwish, F.A.I.; Silva, F.J. Physical nonlinearity of precast reinforced geopolymer concrete beams. J. Mater. Res. Technol. 2019, 8, 2083-2091. [CrossRef]

12. Palanisamy, P.; Kumar, P.S. Effect of molarity in geo polymer earth brick reinforced with fibrous coir wastes using sandy soil and quarry dust as fine aggregate. (Case study). Case Stud. Constr. Mater. 2018, 8, 347-358. [CrossRef]

13. Coppola, L.; Coffetti, D.; Crotti, E.; Marini, A.; Passoni, C.; Pastore, T. Lightweight cement-free alkali-activated slag plaster for the structural retrofit and energy upgrading of poor quality masonry walls. Cem. Concr. Compos. 2019, 104, 103341. [CrossRef]

14. Samal, S.; Phan Thanh, N.; Petríková, I.; Marvalová, B.; Vallons, K.A.M.; Lomov, S.V. Correlation of microstructure and mechanical properties of various fabric reinforced geo-polymer composites after exposure to elevated temperature. Ceram. Int. 2015, 41, 12115-12129. [CrossRef]

15. Demirboga, R.; Kan, A. Thermal conductivity and shrinkage properties of modified waste polystyrene aggregate concretes. Constr. Build. Mater. 2012, 35, 730-734. [CrossRef]

16. Khoukhi, M. The combined effect of heat and moisture transfer dependent thermal conductivity of polystyrene insulation material: Impact on building energy performance. Energy Build. 2018, 169. [CrossRef]

17. Cadere, C.A.; Barbuta, M.; Rosca, B.; Serbanoiu, A.A.; Burlacu, A.; Oancea, I. Engineering properties of concrete with polystyrene granules. Procedia Manuf. 2018, 22, 288-293. [CrossRef]

18. Adam, A.A.; Horianto, X.X.X. The Effect of Temperature and Duration of Curing on the Strength of Fly Ash Based Geopolymer Mortar. Procedia Eng. 2014, 95, 410-414. [CrossRef]

19. Nath, P.; Sarker, P.K.; Rangan, V.B. Early Age Properties of Low-calcium Fly Ash Geopolymer Concrete Suitable for Ambient Curing. Procedia Eng. 2015, 125, 601-607. [CrossRef]

20. Muhammad, N.; Baharom, S.B.; Amirah, N.; Ghazali, M.; Alias, N.A. Effect of Heat Curing Temperatures on Fly Ash-Based Geopolymer Concrete. Int. J. Eng. Technol. 2019, 8, 15-19.

21. Al-Majidi, M.H.; Lampropoulos, A.; Cundy, A.; Meikle, S. Development of geopolymer mortar under ambient temperature for in situ applications. Constr. Build. Mater. 2016, 120, 198-211. [CrossRef]

22. Ismail, N.; El-Hassan, H. Development and Characterization of Fly Ash-Slag Blended Geopolymer Mortar and Lightweight Concrete. J. Mater. Civ. Eng. 2018, 30, 04018029. [CrossRef]

23. Rashid, Y. Thermal and Structural Characterization of Macro-Encapsulated Phase Change Material Integrated Into Concrete Cubes. Master's Thesis, United Arab Emirates University, Al Ain, UAE, 2018.

24. Ayati, B.; Ferrándiz-Mas, V.; Newport, D.; Cheeseman, C. Use of clay in the manufacture of lightweight aggregate. Constr. Build. Mater. 2018, 162, 124-131. [CrossRef]

25. Omnexus. Expanded Polystyrene (EPS): Ultimate Guide on Foam Insulation Material. 2020. Available online: https://omnexus specialchem.com/selection-guide/expanded-polystyrene-eps-foam-insulation\#: \{\}:text=Polystyrene $\% 20$ granulate $\% 20 \mathrm{is} \% 20 \mathrm{pre}$ foamed\%20at,50\%20times\%20its\%20original\%20size (accessed on 14 August 2020).

26. Schneider, E.; Steinweg, J.; Machelett, L.; Giovannetti, F. Solar Assisted Production of Expanded Polystyrene with High Efficiency Flat Plate Collectors. In Proceedings of the 11th ISES EuroSun 2016 Conference, Palma de Mallorca, Spain, 11-14 October 2016; pp. 1-8. [CrossRef]

27. Sen, I. Degradation Mechanism of Expanded Polystyrene (EPS) Foam in Lost Foam Casting, PIPS Approach for Synthesis and Novel Expansion Techniques for Cellular Foam. Ph.D. Thesis, University of Tennessee, Knoxville, TN, USA, 2007.

28. Awbi, H.B. Calculation of convective heat transfer coefficients of room surfaces for natural convection. Energy Build. 1998, 28, 219-227. [CrossRef]

29. Chen, J.; Wang, H.; Xie, P.; Najm, H. Analysis of thermal conductivity of porous concrete using laboratory measurements and microstructure models. Constr. Build. Mater. 2019, 218, 90-98. [CrossRef]

30. Hasan, A.; Alnoman, H.; Rashid, Y. Impact of integrated photovoltaic-phase change material system onbuilding energy efficiency in hot climate. Energy Build. 2016, 130, 495-505. [CrossRef]

31. Ahmad, H.; Khaled, A.-S.; Alnoman, H.; Yasir, R.; Shaimaa, A. Effect of Phase Change Materials (PCMs) Integrated into a Concrete Block on Heat Gain Prevention in a Hot Climate. Sustainability 2016, 8, 1009.

32. Peeters, L.; Beausoleil-Morrison, I.; Novoselac, A. Internal convective heat transfer modeling: Critical review and discussion of experimentally derived correlations. Energy Build. 2011, 43, 2227-2239. [CrossRef]

33. ASTM. Standard Specification for Nonloadbearing Concrete Masonry Units. In ASTM C129-17; ASTM: West Conshohocken, PA, USA, 2017.

34. ASTM International. Standard Specification for Pedestrian and Light Traffic Paving Brick. In ASTM C902-15; ASTM: West Conshohocken, PA, USA, 2015. 
35. Liu, Y.; Tang, W.; Singh, R. Study on Compressive Strength and Water Permeability of Steel Slag-Fly Ash Mixed Permeable Brick. Appl. Sci. 2019, 9, 1542. [CrossRef]

36. Mora, O.; Alvarado, D.; Torres, A. Economic analysis of the application of porous pavements on Bogota roads. In Proceedings of the 12nd International Conference on Urban Drainage, Porto Alegre, Brazil, 11-16 September 2011.

37. Elizondo-Martinez, E.; Andrés-Valeri, V.; Jato-Espino, D.; Rodriguez-Hernandez, J. Review of porous concrete as multifunctional and sustainable pavement. J. Build. Eng. 2019, 27. [CrossRef]

38. Bubeník, J.; Zach, J. The use of foam glass based aggregates for the production of ultra-lightweight porous concrete for the production of noise barrier wall panels. Transp. Res. Procedia 2019, 40, 639-646. [CrossRef] 